\title{
Educação Infantil: tempos e espaços para danças e infâncias
}

\author{
Patricia Dias Prado \\ Faculdade de Educação, Universidade de São Paulo, Brasil \\ patprado@usp.br \\ Milene Braga Goettems \\ Faculdade de Educação, Universidade de São Paulo, Brasil \\ milenebra@uol.com.br
}

\begin{abstract}
Resumo: Este artigo apresenta algumas das análises da pesquisa que busca conhecer e investigar as contribuições da dança no contexto da Educação Infantil, no sentido da construção de uma Pedagogia da primeira infância que valorize os processos pedagógicos fundamentados nas Artes, nos tempos e espaços de infâncias de meninas e meninos pequenos, e de suas/seus professoras/es. Reconhecendo as linguagens da dança como possibilidades de resistência à escolarização precoce e aos tempos do capital, a investigação tem revelado que elas contribuem para a construção de outras referências de tempo e espaço às infâncias e a sua educação, de percepção dos corpos, de criação de movimentos e gestualidades, de descobertas e de relações com o pertencimento e com a diversidade cultural.
\end{abstract}

Palavras-chave: Educação Infantil; Dança; Infância; Tempo e espaço; Processos pedagógicos.

Recibido: 23/02/2019

Aceptado: 19/03/2019 


\title{
Educación Infantil: tiempos y espacios para danzas y infancias
}

Resumen: Este artículo presenta algunos de los análisis de la investigación que busca conocer e investigar las contribuciones de la danza en el contexto de la Educación Infantil, en el sentido de la construcción de una pedagogía de la primera infancia que valorice los procesos pedagógicos fundamentados en las Artes, en los tiempos y espacios de infancias de niñas y niños pequeños, y de sus profesoras/es. Reconociendo los lenguajes de la danza como posibilidades de resistencia a la escolarización precoz y a los tiempos del capital, la investigación ha revelado que contribuyen a la construcción de otras referencias de tiempo y espacio a las infancias y su educación, de percepción de los cuerpos, movimientos y gestos, de descubrimientos y de relaciones con la pertenencia y con la diversidad cultural.

Palabras clave: Educación Infantil; Danza; Infancia; Tiempo y espacio; Procesos pedagógicos.

\section{Early Childhood Education: time and space for dances and childhoods}

\begin{abstract}
This article presents some of the analysis of the research that seeks to know and investigate the contributions of dance in the context of Early Childhood Education, in the sense of the construction of a Pedagogy of early childhood that values pedagogical processes based on Arts, time and space of childhood of young girls and boys, and of their teachers. Recognizing the languages of dance as possibilities of resistance to early schooling and the times of capital, research has revealed that they contribute to the construction of other references of time and space to childhood and its education, the perception of bodies, the creation of movements and gestures, discoveries and relations with belonging and cultural diversity.
\end{abstract}

Keywords: Early Childhood Education; Dance; Childhood; Time and space; Pedagogical processes. 


\section{Introdução}

Este artigo apresenta algumas das análises de pesquisa de mestrado em Educação, (Goettems, 2019), que busca conhecer e investigar as contribuições da dança no contexto da Educação Infantil, no sentido da construção de uma Pedagogia da primeira infância que valorize os processos pedagógicos fundamentados nas Artes, nos tempos e espaços de infâncias de meninas e meninos pequenos, e de suas/seus professoras/es. Reconhecendo as linguagens da dança como possibilidades de resistência à escolarização precoce e aos tempos do capital, a investigação tem revelado que elas contribuem para a construção de outras referências de tempo e espaço às infâncias e a sua educação, de percepção dos corpos, de criação de movimentos e gestualidades, de descobertas e de relações com o pertencimento e com a diversidade cultural.

Apesar dos avanços teóricos e políticos que buscam reconhecer as meninas e meninos pequenos, no presente, por meio de uma Pedagogia que respeite seus direitos de viverem suas infâncias plenamente nos espaços públicos, coletivos e educativos das creches e pré-escolas, ainda convivemos com concepções que as/os enxergam no futuro. Tais concepções estão fundamentadas numa perspectiva de progresso e evolução linear das crianças e objetivam medir seu desenvolvimento a partir de modelos pré-estabelecidos e prepará-las para o Ensino Fundamental (Prado, 2015a).

Sayão (2008) afirma que é preciso aprender com as crianças sobre elas próprias, mas para isso é importante buscar conhecer os significados das dimensões aparentes ou simbólicas da educação dos corpos de meninas e meninos, quando estão juntas com outras crianças, com adultas/os, com os objetos e com os espaços e tempos destinados às crianças nas instituições educativas voltadas para a infância, analisando as construções culturais que se produzem sobre e a partir do corpo, incorporando, nesse sentido, outros modos de conceber e produzir o tempo.

A temática aqui proposta não é inédita no campo da Educação, mas o que se observa é a fragilidade das instituições infantis e da formação de professoras/es na construção de culturas da infância, a partir das culturas infantis (Fernandes, 2004; Perrotti,1982). Através da mediação com o outro que ensina, aprende e faz junto, as crianças constroem seu mundo de cultura, que depende, em parte das/os adultas/os, em alguns momentos, mas também da interação das crianças sem sua intervenção (Goettems, 2012; Prado, 2012). Em ambos momentos, os processos pedagógicos podem estar fundamentados nas artes e evidenciarão, pelas próprias crianças, suas corporeidades expressivas, dançantes, teatrais, performáticas, em suas gestualidades e movimentos, em suas relações na diversidade e em suas brincadeiras, desde o nascimento (Prado, 2015b).

Levando em conta o desenvolvimento de um trabalho que possibilite respeitar e valorizar as diferentes linguagens das crianças:

Faz-se necessária uma outra formação profissional docente (formação + pesquisa=inovação), também sofisticada, e uma pedagogia para a infância que não seja apenas sinônimo de ler e escrever, que não faça da palavra um atalho para o conhecimento (Malaguzzi, 1988), com professores/as capazes de trabalhar com idades misturadas, em duplas de adultos sem hierarquia, alfabetizados nas cem linguagens, críticos das pedagogias espontaneístas e cognitivistas, superando os binarismos, o adultocentrismo, o sexismo, o racismo, enfim todos os preconceitos e desigualdades (Faria \& Ritcher, 2009, p. 110).

De acordo com Barbosa (2013) observa-se atualmente, nas instituições de Educação Infantil, o tempo do capital como uma pedagogia implícita e que as manifestações dessa pedagogia estão presentes em diversos elementos como, por exemplo, na ausência de tempo para as crianças brincarem, priorizando o tempo para desenvolver habilidades 
que as preparem para o futuro; o modo como são apressadas para atender aos horários das instituições; a fragmentação do tempo para a realização de atividades sem sentido pessoal e a priorização da realização de tarefas em que não é considerado o processo, mas sim, o produto final.

A regulação temporal que caracteriza a vida contemporânea com a tríade produção-acumulação-consumo atropela e desapropria o tempo da vida. Para dar conta dessa regulação são construídos nas escolas artefatos como cronogramas, horários, rotinas, que, ao invés de organizar o coletivo, mais o controlam. Um tempo que é vivido apenas como tempo cronológico, linear, sequencial. Todo o tempo investido livremente pelas crianças nas coisas que lhe dizem respeito (...) é visto como perder tempo. Portanto, o que encontramos nas escolas infantis é a presença desse tempo característico das relações capitalísticas, que brutaliza a vida cotidiana e empobrece a experiência da infância (Barbosa, 2013, p. 216).

Segundo Thompson (1991) no sistema capitalista: “[...] todo o tempo tem de ser consumido, comprado, posto em uso; é ofensivo das classes trabalhadoras permitir-se-lhes simplesmente passar o tempo” (p. 77).

Para Bauman (2003) as instituições rígidas da modernidade sólida, como as instituições escolares, já não comportam os sujeitos ágeis, instáveis e mutantes, que vão sendo moldados no interior de novas experiências engendradas na modernidade líquida. Na modernidade líquida pode-se dizer que há um novo tipo de dominação, ou seja, o controle antes realizado por meio da rigidez e do controle, principalmente, através dos espaços. A falta de tempo é a justificativa para as novas formas de dominação através do tempo. O tempo é a regulação para o aprisionamento das pessoas.

A produção recente no campo das pesquisas em Educação Infantil, no Brasil, também tem revelado que grande parte das instituições de Educação Infantil segue o referencial de organização escolar do Ensino Fundamental. Entendemos que deveria ser o contrário: espaços e tempos educativos devem ser construídos e organizados como processos pedagógicos de vivência plena das infâncias, que priorizem a comunicação de corpos inteiros, de movimentos, gestualidades, linguagens teatrais, dançantes e brincantes de crianças e professoras/es da Educação Infantil, inspirando a educação das crianças maiores na escola.

Souza (2016), Silva (2017) e Prado (2017b) ressaltam as linguagens artísticas, especialmente, as teatrais e performáticas (Machado, 2010), como formas de construção de culturas entre as crianças e entre elas e as/os profissionais da infância (professoras/es, artistas e pesquisadoras/es), nos espaços educativos de Educação Infantil e fora deles, como nos teatros, praças, ruas, etc. Entretanto, sabe-se que essas linguagens estão reprimidas nas/os adultas/os, furtadas delas/es pelo mundo do trabalho no capitalismo (Marcellino, 1990) e precisam ser reaprendidas e reconstruídas no processo de formação docente das/os profissionais da infância (Franco, 2001).

As crianças compreendem o mundo através das brincadeiras, sendo estas as principais condições para a construção de culturas entre seus pares, contribuindo para o desenvolvimento da "[...] criatividade e da inventividade de meninos e meninas, deixando-as ser crianças" (Gobbi, 2011, p. 131), trazendo consigo sonhos, sentimentos, desejos que precisam ser respeitados.

Assim como afirma Miller (2012, p. 96): “[...] o corpo presente já é vivenciado pela criança como reflexo de sua relação com a vida quando ela brinca e conquista possibilidades de ações e experiências múltiplas do cotidiano”. As propostas em dança desenvolvidas com/para as crianças emergem da qualidade dessas vivências de brincantes, encorajando-as a brincar com o próprio corpo e a perceber o que acontece no momento presente, em que a prioridade é o ato em si, além do processo, e não o resultado do ato executado. 
Os interesses trazidos pelas crianças, seus conhecimentos e contextos concretos são a condição, segundo Freire (2008), para o "desenvolvimento de novos saberes a educação dialógica parte da compreensão que as crianças têm suas experiências diárias e que começar a partir delas é partir do concreto, do senso comum, para chegar a uma compreensão mais profunda da realidade" (p. 131):

[...] da educação que, não podendo jamais ser neutra, tanto pode estar a serviço da decisão, da transformação do mundo, da inserção crítica nele, quanto a serviço da mobilização, da permanência possível das estruturas injustas, da acomodação dos seres humanos à realidade tida como intocável (Freire, 2000, p. 58).

Vale ressaltar que a formação tecnicista parte dos modelos tayloristas e fordistas do início do século XX, que influenciaram fortemente o modelo de escola que conduz ao aprendizado da obediência e da submissão, tanto ao sistema, quanto aqueles/as que estavam nos patamares hierárquicos superiores. Dessa forma, a escola foi chamada a contribuir com a ideia de sociedade produtivista, reproduzindo no âmbito educativo o processo de atomização gerado na esfera trabalhista.

[...] a produção histórica da América Latina começa com a destruição de todo um mundo histórico, provavelmente a maior destruição sociocultural e demográfica da história que chegou a nosso conhecimento [...] Uma das mais ricas heranças intelectuais e artísticas da espécie não só ficou destruída, mas, sobretudo sua parte mais elaborada, mais desenvolvida e avançada, ficou inacessível para os sobreviventes desse mundo (Quijano, 2005, p. 16).

De acordo com Quijano (2005), o novo sistema de dominação social teve como elemento fundador a ideia de raça, que foi a primeira categoria social da modernidade. Isso resultou na imposição de uma única identidade, destituindo os povos latinos e africanos de suas plurais identidades, memórias e conhecimentos. A ideia de raça, portanto, é criada para dar sentido às novas relações de poder, redefinindo e configurando todas as formas e instâncias prévias de dominação. As práticas pedagógicas, nesse sentido, precisam ser vistas em sua realidade e não na busca por mudanças baseando-se no cientificamente correto. É muito comum nas pesquisas, a reprodução do discurso vigente, esquecendo-se de fazer a pesquisa propriamente dita.

O poder hegemônico eurocêntrico distorce e bloqueia a percepção de nossa experiência histórico-cultural. A colonialidade do poder faz da América Latina um cenário de des/encontros entre nossos conhecimentos. É fundamental, desta forma, liberar nossa retina da prisão eurocêntrica e reconhecer nossas experiências históricas.

Auroux (1992) discute a questão da padronização e pedagogização das línguas que se justificaram necessárias para o desenvolvimento da Ciência. Entretanto, a língua como um referencial identidário, contribui para uma padronização escolar e sabe-se que essa padronização produz desigualdades, visto que cada contexto é único. Mesmo os grupos que tentam fugir da padronização acabam sendo pegos pelo sistema econômico.

A identidade cultural individual e coletiva é dinâmica e está em constante construção. Em uma sociedade capitalista, marcada pelo consumismo, essa construção é influenciada pelas demandas do consumo e pelo tempo linear. Reside neste ponto uma contradição social, pois a construção da identidade pressupõe que as pessoas possam se desenvolver em suas diferentes dimensões e não apenas pelo viés do tempo do capital.

Nesse sentido, ao discutir a questão de um tempo artístico e, sobretudo, educativo, que rompa com a experiência do tempo linear característico das relações capitalistas, pretende-se buscar, por meio da linguagem da dança, formas de descolonização das infâncias nas creches e pré-escolas (Aquino, 2015), e de reconhecimento de suas identidades 
sociais e culturais, através e a partir dos corpos. Para Laban (1978), os corpos são instrumentos através dos quais os humanos se comunicam e se expressam. E, por isso, "[...] as ações corporais que forem executadas com uma consciência imaginativa estimularão e enriquecerão a vida interior” (p. 131).

Um importante passo para ampliar as reflexões acerca dos corpos e movimentos das professoras nas instituições de Educação Infantil, bem como, da reconstrução de suas dimensões brincalhonas, é reconhecer as crianças pequenas produzem culturas e que precisam urgentemente ser vistas e ouvidas, com suas capacidades de criar, imaginar, inventar e representar papéis, brincar com seus corpos, se relacionar com outras crianças e com as/os professoras/ es, das mais diversas formas, comunicando-se através de sua corporeidade e expressando-se por meio de múltiplas linguagens (Edwards, Forman e Gandini, 1999). É essencial criar possibilidades para que estas manifestações aconteçam e estar disponível corporalmente para senti-las e percebê-las, apropriando-se de todos esses elementos para a construção de uma pedagogia da Educação Infantil que reconheça efetivamente os direitos das crianças pequenas.

De acordo com Bufalo (1997), as expressôes corporais não estão desvinculadas das manifestações culturais das diferentes etnias, gêneros, idades e classes sociais. Existe uma integração entre corpo e mente na linguagem pele-pele, que possibilita uma relação entre as pessoas de diferentes características e as aprendizagens decorrentes deste contato. Dessa forma:

A dança, dentro de um contexto social, é de grande importância como auxiliar na valorização de um pensamento crítico transformador, articulando a linguagem corporal com a verbal, conectando-as a conteúdos pedagógicos que garantam auto-conhecimento e fortalecimento social (Tadra; Viol e Ortolan, 2009, p. 53).

Segundo Sabino e Lody (2011) é importante perceber e valorizar as manifestações intangíveis que estão em processos patrimoniais da sabedoria e elementos culturais dos povos, no que se refere às músicas, dança, culinária, tecnologias, indumentária, entre outras maneiras de revelar suas identidades e alteridade, que se refere ao diálogo e à valorização das diferenças existentes.

Os valores e princípios culturais podem ser representados através do conjunto de posturas e movimentos corporais, dessa forma, atuar no corpo significa atuar sobre a sociedade na qual esse corpo está inserido. Nesse sentido, as práticas institucionais que envolvem o corpo (educativas, artísticas, recreativas ou reabilitadoras) devem ser pensadas nesse contexto, para evitar sua realização de forma reducionista, considerando os seres humanos como sujeitos da vida social (Daolio, 1995).

As crianças, portanto, são “[...] seres capazes de saber, de saber que sabem, de saber que não sabem. De saber melhor o que já sabem, de saber o que ainda não sabem” (Freire, 2000, p. 40). Para que se ampliem as possibilidades das crianças e de sua existência humana no mundo é importante compreender suas diferentes formas de expressão em diferentes contextos sociais.

Freire e Macedo (1990) propõem uma educação que valorize e respeite as diferenças culturais e os saberes e as experiências de vida dos sujeitos, considerando que: “[...] compreender a realidade do oprimido, refletida nas diversas formas de produção cultural - linguagem, arte, música, leva a uma compreensão melhor da expressão cultural mediante a qual as pessoas exprimem sua rebeldia contra os dominantes" (p. 85).

Pensando nos discursos e ideologias sobre a infância, Foucault (1971) nos fala que o poder está relacionado com aquilo que seria um processo ordenado de produção de discursos em nossas sociedades e que "o discurso não é simplesmente aquilo que traduz as lutas ou sistemas de dominação, mas aquilo pelo qual e com o qual se luta, é o próprio poder de que procuramos assenhorar-nos" (p. 3). 
De acordo com Arelaro (2005), a Educação Infantil é o único nível ou etapa de ensino que foi criado com o atendimento de cima para baixo. Essa organização priorizava o atendimento das crianças de 6, 5 e 4 anos, nesta respectiva ordem, com o objetivo de garantir o sucesso escolar, quando chegasse o momento do letramento. As escolas foram organizadas para se aculturarem ao modo de produção capitalista, o que aponta necessariamente para a formatação de uma educação escolar da infância objetivando a maior eficácia nas etapas seguintes. Em outras palavras, para a redução do ser humano, desde a sua infância, há uma força geradora de lucro e consumidora de bens e serviços.

Trata-se, portanto, do oposto do que defendemos aqui: a concepção de que as crianças devem viver seu tempo de infância em sua plenitude, construindo suas próprias culturas e não serem vistas, como afirma Faria (1999), apenas do ponto de vista biológico, como um vir-a-ser, mas percebê-las na sua dimensão cultural, respeitando as especificidades da infância enquanto momento a ser vivido no seu tempo.

Nesse sentido, considerar que as crianças pequenas constroem culturas, saberes e conhecimentos, requer consolidar uma Pedagogia da Educação Infantil que considere a brincadeira como eixo (Brasil, 1995/2009), na organização e planejamento dos tempos e espaços educativos de forma flexível, através de processos pedagógicos que não priorizarem somente as questões cognitivas, associadas ao encadeamento linear e lógico, abrindo-se para a dimensão do novo que trazem as criança (Larrosa, 2004), a favor de tempos e espaços artísticos, presentes e das infâncias.

\section{Tempos e espaços dançantes na Educação Infantil}

A dança é a arte do espaço em mutação infinita. Dançamos com e no espaço, e também com o que ele contém (Xavier, 2014, p.05).

A origem da concepção de espaço que temos na atualidade é herança de um processo que foi se constituindo há milhares de anos. As concepções sobre o espaço nas teorias renascentistas e euclidianas tornaram-se um modelo que influenciaram valores estéticos e um paradigma de conhecimento. Ou seja:

[...] a herança do espaço euclidiano é o dele ser pensado como figura geométrica abstrata, desprovida de matéria, estático, plano, imutável, pressupostamente divorciado da experiência, restrito à geometria, matemática, medições, deduções lógicas, fronteira, lugar, linha, ponto, plano (Banana, 2015, p. 62).

Na mesma lógica, Banana (2015) afirma que Newton compreende o espaço "como objeto geométrico [...] como algo que já vem pronto e necessário para que tudo mais o preencha. Ortogonal (tridimensional), atemporal, homogêneo, estático, imutável, independente da nossa experiência. Trata-se de um espaço que nunca se modifica” (p. 65).

Essa concepção é a do espaço absoluto: “é o espaço que não teria relação com as coisas externas, isto é, o espaço que não dependeria dos corpos ou outra coisa qualquer para existir. Esse espaço se caracteriza pela sua imutabilidade eterna (Sapunaro, 2012, p. 41 apud Banana, 2015, p. 65).

A concepção de espaço homogêneo, neutro, atemporal e geométrico ainda é predominante, entretanto, atualmente as conquistas científicas dos séculos XIX e XX contribuíram para pensar em um espaço que não seja divorciado do tempo, podendo ter inúmeras dimensões:

[...] ser dinâmico, vivo, mutável, não restrito à geometria, às ciências ditas "duras" como a física e a matemática, mas pode e deve ser vivido como resultado de relações humanas, ou seja, econômicas, sociais, culturais. E, que as artes devem ser consideradas fundamentais na produção de espaços possíveis, mesmo 
que se tornem necessários ao passarem a existir e, ainda, que neste caso, uns são tão válidos quanto os outros (Banana, 2015, p. 68).

Apesar dessa nova concepção sobre o espaço e o tempo, ainda precisamos enfrentar muitas barreiras, no que se refere à concepção dos espaços e tempos nas instituições de Educação Infantil. Não se trata apenas dos espaços físicos das instituições, mas também do respeito aos espaços como propriedade do próprio corpo, que não está dissociado do tempo.

De acordo com Salzstein (2015), os múltiplos espaços dentro do corpo referem-se a um espaço como vazio, algo que circundaria o corpo e se estenderia para além dele, ou seja, não é ambiente, exterioridade, mas sim, espaço como processo, pura plasticidade, mobilidade de formas, sutileza e leveza de estruturas em movimento.

Sem a dimensão da experiência, da qual o corpo é o único garantidor, o espaço perde essa dimensão dinâmica, é mera abstração. Nesse sentido, corpo, tempo e espaço podem ser entendidos como uma única e mesma instância: “[...] a ideia da conquista do corpo como movimento e plasticidade está profundamente ligada à premissa de que o sujeito não é uma categoria estável, já dada, mas sim uma instância a ser formada, forjada ao longo da vida” (Salzstein, 2015, p.21).

Essa ideia vem ao encontro de Lopes (2015), pois:

A produção da corporalidade se faz no processo de transformação e em reação ao espaço circundante. Duração de tempo com o que o corpo interage com o espaço e tudo que está contido nele estimula o corpo a se transformar, a se recriar, a acontecer, enfatizando assim o potencial performático da dança. O corpo, em suas diferentes realidades, torna-se um dispositivo de transmissão de temporalidade, espacialidade e de auto-reflexibilidade (p. 33).

Foi a partir da Arte Moderna, sobretudo, a das vanguardas, que deixou de se falar em um corpo em abstrato. Essa corrente tematizou um corpo que se recusava à instrumentalidade e à funcionalidade, e questionou implacavelmente a promessa de desempenho e eficiência da sociedade tecnológica, assim como, a ideia de que se podia delegar à técnica a tarefa de administrar a vida. Na contracorrente dessa visão do corpo funcional/instrumental, as/os artistas de vanguarda buscaram o espaço da vida comum e a experiência de um corpo imanente, ou seja, inseparável. Ao longo da primeira metade do século XX houve uma radicalização dessa experiência, na qual corpo e espaço aparecem desierarquizados.

\section{A dança na Creche/Pré-Escola pesquisada}

Buscando contribuir para a construção de metodologias de pesquisa com crianças (alfaria, De Martin e Prado, 2009), no sentido de sua decolonização e reconhecendo as relações entre Educação Infantil, diversidade e arte na primeira infância (Prado e Souza, 2017), foi realizada pesquisa de campo, com observação participante nas propostas de dança, em uma das Creches/Pré-Escolas da Universidade de São Paulo/USP, com dois grupos de meninas e meninos de 5 anos de idade, filhas/os de funcionárias(os), docentes e discentes da Universidade, e sua professora de dança ${ }^{1}$, mediante autorização prévia.

\footnotetext{
${ }^{1}$ Formada em Magistério e em Dança. Professora de dança, há mais de 16 anos na Creche/Pré-Escola pesquisada.
} 
Cada grupo era formado, aproximadamente, por 12 crianças e a cada semana os grupos se alternavam para participarem das propostas de dança, de 60 minutos. A frequência e o período das observações foram de uma vez por semana, portanto, durante o ano letivo de 2016, além de estenderem-se para os momentos das Festas Junina e de encerramento. Os dados coletados foram registrados em caderno de campo, por meio de fotografias e de filmagens em vídeo, de conversas informais com as crianças e coleta de materiais produzidos nas propostas de dança, como desenhos, além da realização de entrevista semiestruturada com a referida professora de dança.

As fotografias elegidas neste artigo, como as Imagens 1, 2, 3, privilegiam somente uma das muitas propostas em dança observadas em campo, qual seja, "Dançando com Picasso", que teve a duração de aproximadamente um mês. Aqui, assim como na pesquisa, elas são concebidas como fontes documentais, são um recorte, uma intenção de registro do(a) pesquisador(a) em determinados momentos e não significam testemunhos empíricos ou verídicos, mas sim, "como algo que colabora com a produção do conhecimento e, como tal, pode ser tratada como representação social, produto material e segmento de relações sociais, evidenciando-as" (Gobbi, 2011, p.1220). É imprescindível, dessa forma, o estranhamento das imagens, cultivando um olhar crítico para que não sejam incorporadas de modo conservador ou alienado, pois não podem ser consideradas como cópias da realidade, mas como insinuações da mesma, que não substituem o texto escrito.

As Creches/Pré-Escolas da USP têm acumulado, ao longo dos anos de sua existência, uma extensa produção acadêmico-científica e são referências fundamentais para a comunidade acadêmica, para os avanços científicos e para as lutas políticas e sociais da Educação Infantil (Arelaro, 2005). Em um levantamento realizado no período de 2009 a 2014, as Creches/Pré-Escolas da USP participaram ou contribuíram, como campo de pesquisa, para a realização de 99 Teses de Doutorado, Dissertações de Mestrado e Iniciações Científicas (Comissão, 2015). Além disso, as/os profissionais das creches foram autoras/es de 182 trabalhos apresentados em eventos acadêmico-científicos.

No que se refere à contribuição para a formação profissional, as cinco Creches/Pré-Escolas da USP receberam, no mesmo período, 681 estagiárias/os dos mais diversos cursos, como Pedagogia, Educação Física, Psicologia, Enfermagem, Terapia Ocupacional, Nutrição, Odontologia, Fonoaudiologia, Música, etc. Em Extensão e Cultura Universitária, apenas entre 2009 a 2014, as Creches/Pré-Escolas uspianas, que mantêm um programa semanal de visitação externa, por exemplo, receberam mais de 6.600 pessoas vindas de todo o Brasil e do exterior (Comissão, 2015).

No primeiro dia de observação, o(a) pesquisador (a) foi convidado(a) a entrar na roda e se apresentar para todas as crianças. Uma delas olhou para seus pés e disse: - "Você precisa tirar os sapatos e a meia, e também deverá prender seus cabelos". Depois da preparação solicitada, seguida da apresentação e consentimento das crianças para a realização da pesquisa, uma das crianças perguntou: - "Então, você veio conhecer a nossa dança criativa?”2

As atividades de dança eram realizadas, geralmente, em um espaço multiuso. Uma sala grande, onde as crianças eram recepcionadas com oficinas no período da manhã, utilizada como espaço para dormir, almoçar, lanchar e para brincadeiras nos dias de chuva. Também era um espaço de circulação de pessoas e isso interferia no trabalho com as crianças, pois, às vezes, um barulho ou movimentação diferente, tirava o foco das propostas em curso.

\footnotetext{
${ }^{2}$ Quando questionada sobre o que seria essa dança criativa, a professora respondeu que não mais a nomeia desta forma, pois concebe a dança como criativa por princípio, apesar de algumas crianças ainda a chamarem assim.
} 
A escolha deste espaço, entretanto, se deve ao fato de ser amplo e por falta de outro mais apropriado e disponível para esse tipo de atividade. Para Carlos (1996), as relações que as crianças mantêm com os espaços habitados se revelam diariamente nos modos de seus usos. É o espaço capaz de ser sentido, pensado, construído e vivido através e pelos corpos. Nesse sentido, o espaço não existe a priori, ele se constitui e é criado a partir das interações e das relações humanas. Podemos nos questionar, desta maneira: precisamos de um espaço (lugar físico) para as propostas em dança, ou podemos atribuir esse valor a um espaço qualquer? Como se dá a relação com os espaços concretos, imaginários e subjetivos que as crianças apresentam através dos seus movimentos?

As propostas em dança iniciavam com uma roda e a professora solicitava para sentar um menino e uma menina, alternadamente. Era uma forma de propor novos grupos mistos, diferentes dos que se formavam entre as crianças, somente com meninos ou com meninas. Juntas/os cantavam uma música de abertura da atividade: “-Tum, tum, tum, quem está aí?". As crianças uniam as palmas das mãos e mexiam primeiro os dedos mindinhos e os polegares. “-É a dona Mariquinha que acaba de chegar, olê, olê, olê, olê, olê, olá". Juntavam os dedos anelares e indicadores. “-Olê olê olê, olê olê olá”. Cruzavam os dedos maiores. “-Oi cumpadi, oi cumadi”. Juntavam as palmas das mãos e as direcionavam para o lado direito do rosto e para o lado esquerdo, e terminavam com o som de beijinhos estalados.

Nos primeiros encontros com as crianças foi desenvolvido um trabalho de consciência corporal por meio da dança, dos movimentos das articulações com a utilização de objetos, como um esqueleto do corpo humano, imagens por meio dos livros e pôsteres e, principalmente, os próprios corpos das crianças, da professora e do(a) pesquisador(a), como fontes de conhecimentos sobre os músculos, os ossos, a pele, as articulações...

Ferreira (2009) coloca que, no que se refere à dança, podemos lembrar da técnica Klaus Vianna, que ressalta a necessidade da consciência corporal, ou seja, como se dá o funcionamento dos corpos, seus limites e possibilidades, para que, a partir dessa consciência, a dança venha a se manifestar.

[...] a dança acontece quando o corpo está disponível ao movimento, possibilitando a manifestação da dança de cada um. O trabalho de consciência corporal pode estimular nossos sentidos, melhorar nossa compreensão e aceitação de si e do outro. Este trabalho requer momentos de introspecção, nos quais entramos em contato com imagens que podem nos auxiliar no desenvolvimento do processo de individuação (p. 35).

Para Miller \& Neves (2013), nem sempre há a consciência, durante o movimento, de tudo que está ocorrendo no nosso corpo. Entretanto, se for desenvolvida a escuta do movimento, poderemos estar conscientes de muitos acionamentos musculares, das sensações, intenções e imagens que acontecem enquanto nos movemos e das relações de troca que estabelecemos com o ambiente. No caso deste artigo, com os tempos e espaços das danças e infâncias na Educação Infantil, já que os dados analisados revelam a possibilidade não somente de diversas e distintas formas de dançar, como também, de educar crianças e adultas/os, potencializando a dimensão brincalhona das infâncias de ambas/os (Anselmo, 2018).

Nas propostas de dança a professora também realizava com as crianças alongamentos divertidos, utilização de materiais como, por exemplo, mini guarda-chuva, bola, bexiga, corda, tecido, histórias, imagens, músicas, vídeos e fotografias inspiradoras para composição de cenas dançantes com as crianças. Solicitava a realização de desenhos como uma forma de registro das atividades desenvolvidas. Além disso, promovia oficinas de confecção e reforma dos trajes utilizados na festa do Boi, com a participação dos familiares e das crianças. 
Em maio de 2016, a professora iniciou o desenvolvimento de propostas em dança para a Festa do Boi $^{3}$, que aconteceria de junho a novembro, uma tradição que foi trazida e aprimorada por ela, por conta de suas vivências, trajetória e formação nas Danças Populares Brasileiras. Durante os ensaios para a Festa, a professora relembrava alguns elementos do trabalho corporal que foram desenvolvidos com as crianças no decorrer do primeiro semestre, como o movimento das articulaçôes, as torções, movimentos de expandir e encolher, as diferentes possibilidades de apoios dos pés, a percepção do outro e a escuta do próprio corpo. Essa percepção corporal trouxe repertório às crianças para o desenvolvimento das danças que foram apresentadas na Festa Junina e na festa de encerramento do ano. Vale ressaltar que as danças apresentadas pelas crianças e professoras não foram compostas por movimentos padronizados.

Em agosto do mesmo ano, a professora recuperou com as crianças uma visita que fizeram a uma exposição de obras de Pablo Picasso ${ }^{4}$, como inspiração para as propostas em dança. Esse trabalho revelou que as experiências vividas pelas crianças, para além das atividades de dança, eram ressignificadas, oportunizando as mesmas a continuarem suas reflexões, mas a partir de seus corpos e da dança. Nesse sentido, "[...] o movimento humano, muito mais do que uma ação corporal, é o diálogo que o sujeito estabelece com o mundo é sempre intencional e carregado de sentidos e significados" (Almeida, 2016, p.21).

Como na semana anterior as crianças tinham ido visitar uma exposição do Pablo Picasso, a professora articulou elementos das artes plásticas com a dança. Trabalhou com três obras de Picasso: A vida; As senhoritas de Avignon e Mulheres correndo na praia. Ela mostrou para as crianças essas imagens e foi explorando-as junto às crianças, fazendo-lhe perguntas: “-Por que essas pessoas estão tristes?”. Referindo-se à obra A vida: “Como estão seus corpos?”. As crianças diziam: “-Estão tristes porque estão se abraçando. -Por que estão sem roupa, porque estão descalças”. Algumas disseram que pela guerra. Uma delas sabia que era de Picasso na ocasião da morte de seu melhor amigo. A professora lembrou também das fases Cubistas, Rosa e Azul do autor (Caderno de Campo, 08/2016).

A professora espalhou os quadros de Picasso pela sala e a proposta era que as crianças os representassem em gestos, em pequenos grupos. Cada criança e grupo evidenciaram formas distintas e poéticas de interpretação gestual das obras (como nas Imagens 1 e 2), dançando, ao seu modo, ao som de uma música com ritmo castelhano. Em momentos de pausa da música, propostos pela professora, os grupos escolhiam uma das obras e se revezavam para expressá-la. Essa dinâmica negava o aprisionamento dos movimentos das crianças e despertava liberdade de imaginação, bem como de criação, a partir da expressão dos seus corpos. Para desmanchar as poses, a professora propôs que as crianças imaginassem que eram um castelo de areia na praia e se desmanchassem, provocando as crianças a vivenciarem outras formas e possibilidades de movimentos, do uso do espaço e do tempo, além da consciência corporal e de mais brincadeiras com os corpos (Almeida, 2016).

\footnotetext{
${ }^{3} \mathrm{O}$ Bumba Meu Boi é a festa mais marcante da cultura popular da região maranhense. Em homenagem ao protetor do auto, São João, a festa acontece, principalmente, entre os meses de junho e julho. Trata-se uma festa democrática, que envolve pessoas de todas as idades e extratos sociais. Recuperado de: http://bumba-meu-boi.info/bumba-meu-boi-do-maranhao.html.

${ }^{4}$ No Instituto Tomie Ohtake em São Paulo, com a mostra "Picasso: mão erudita, olho selvagem”, no dia 22 de maio de 2016. Pablo Picasso foi pintor, escultor e desenhista espanhol (1881-1973), um dos criadores do movimento artístico cubista.
} 


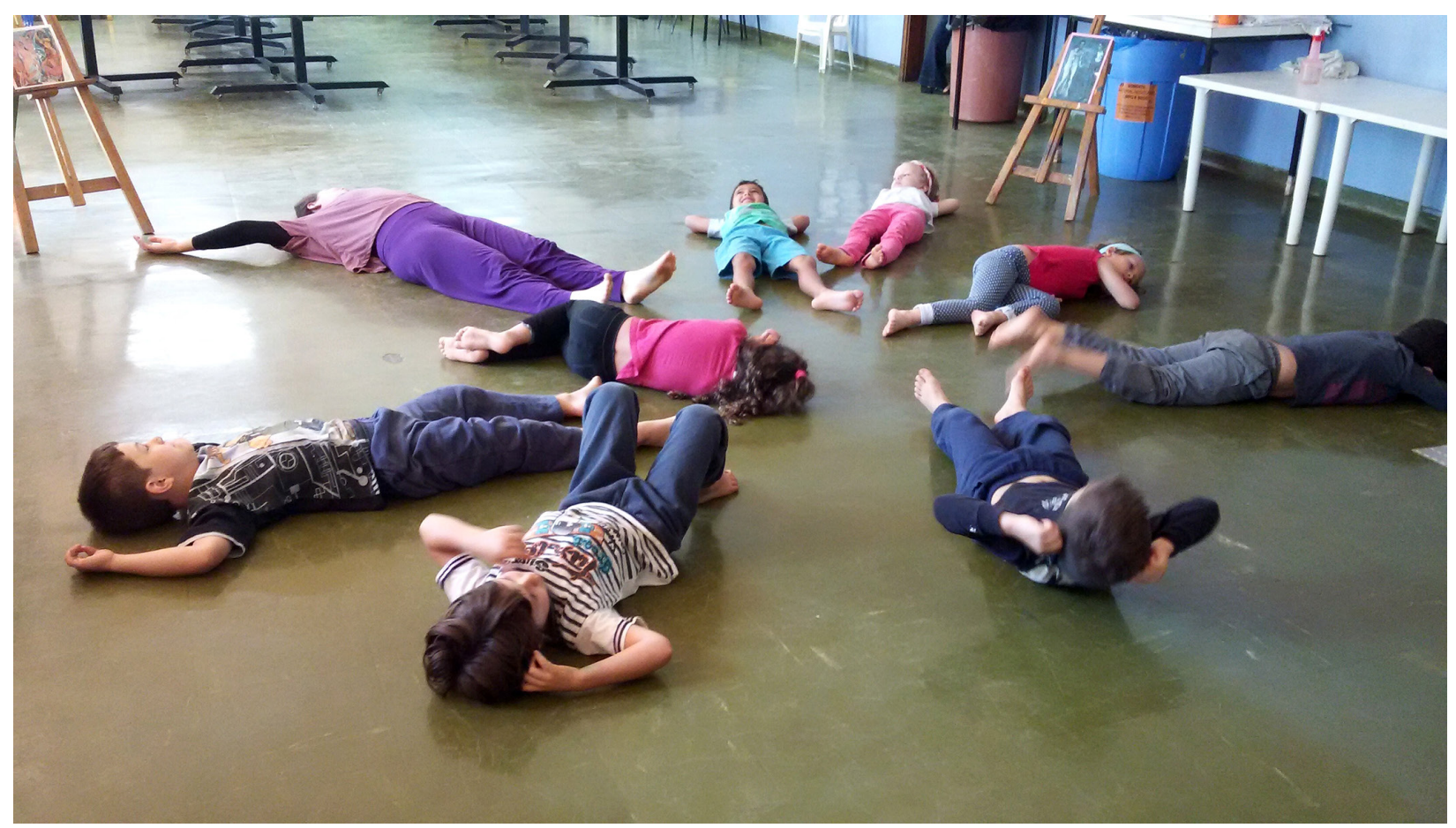

Imagem 1. Crianças e professora nas propostas em dança. Creche/Pré-Escola pesquisada, agosto 2016. Arquivo da pesquisa.

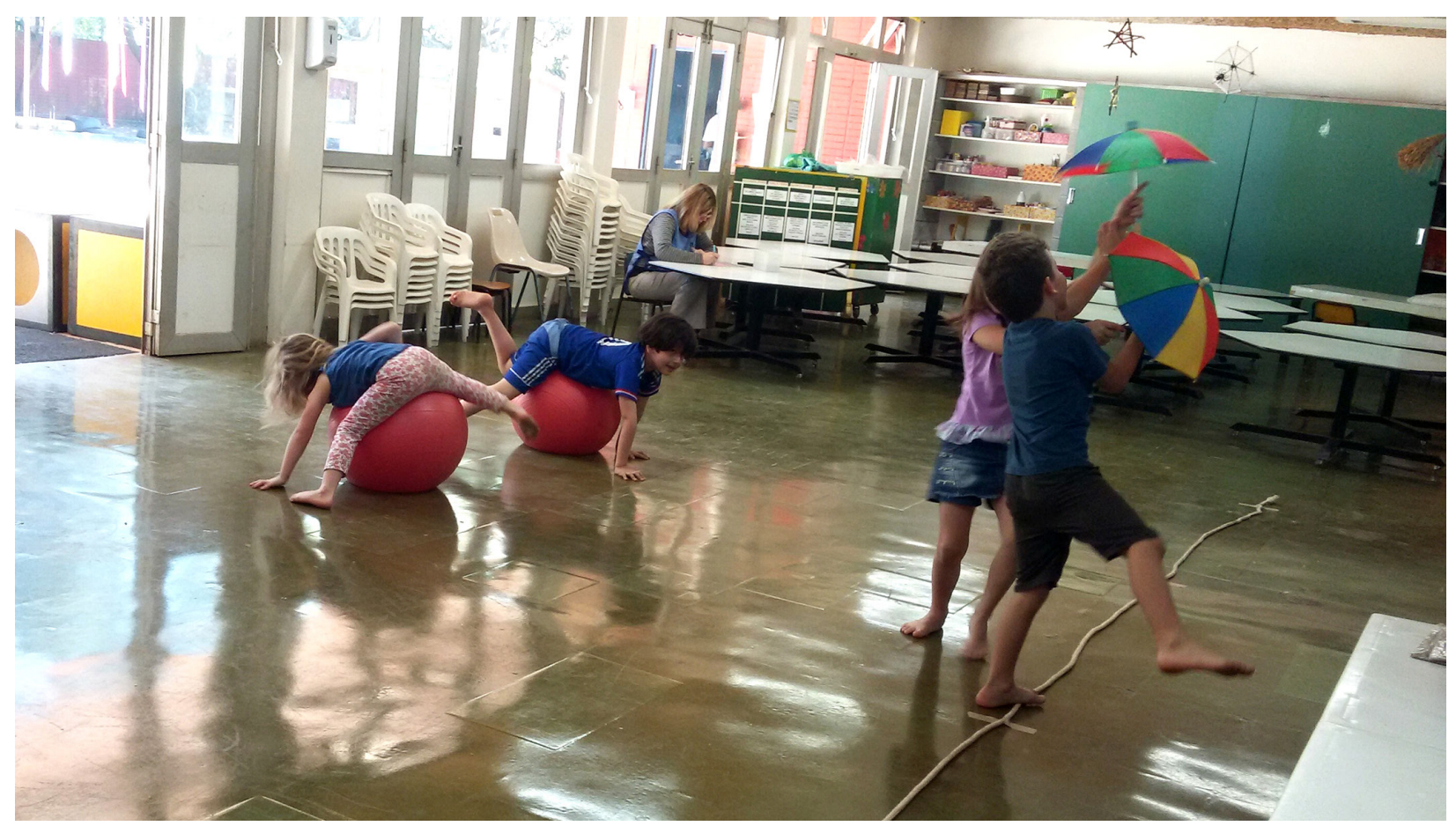

Imagem 2. Crianças dançando com Picasso. Creche/Pré-Escola pesquisada, agosto 2016. Arquivo da pesquisa. 
Outra proposta a partir das obras de Picasso foi a leitura de sua tela "Família de acrobatas malabaristas" (1905), em que as crianças observavam a pintura e falavam sobre suas impressões. Depois a professora organizou o espaço com corda, bolas, sombrinhas de frevo e bexigas. Propôs que cada dupla de crianças brincasse com esses objetos e experimentasse todos. Num canto ficavam as bolas grandes de borracha e a proposta era que as crianças brincassem com seus corpos sobre as bolas; em outro canto ficavam as bexigas cheias e a proposta era brincar com elas sobre seus corpos e, por fim, as crianças brincavam de andar com a sombrinha de frevo pela corda buscando o equilíbrio (como na Imagem 3).

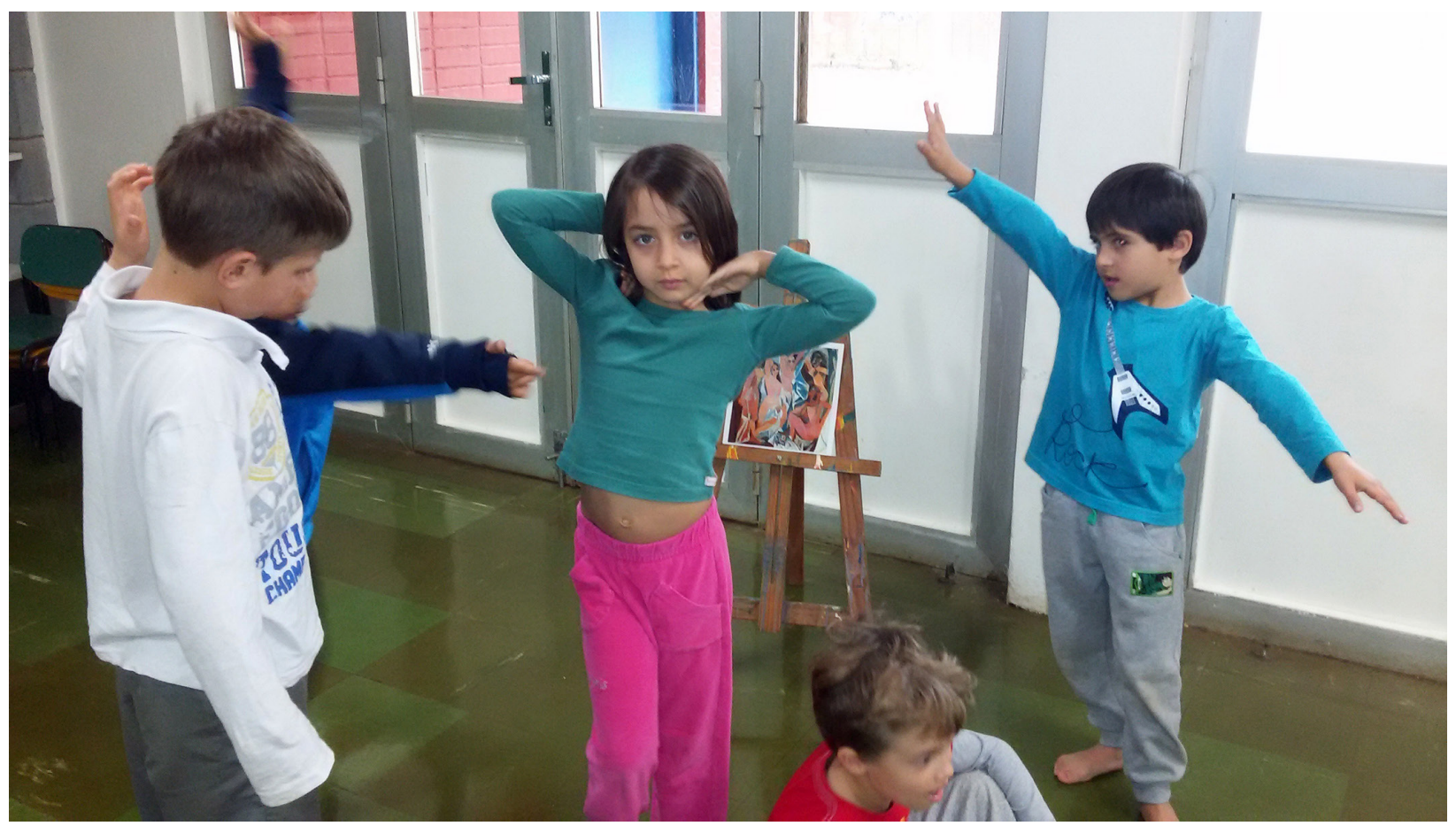

Imagem 3.

A partir destas observações, as concepções de Laban (1978) foram reconhecidas nas propostas da professora, no sentido de apontar diversas possibilidades de emprego do movimento, menos restritas e mais criativas, de acordo com nossos movimentos globais.

Laban nos ensinou que com o corpo adquirimos conhecimento. Ele, já na sua época, dizia que não é possível separar conceitos abstratos, ideias e/ou pensamentos, da experiência corporal. Esta é a base primeira do que podemos dizer, pensar, saber e comunicar [..] (Rengel, 2006, p. 122).

Para além da reprodução das imagens de Picasso, as crianças interpretaram imagens estáticas em forma de movimentos e gestos. Xavier (2007) discute a diferenciação entre movimento e gesto, e afirma que o primeiro refere-se ao resultado do esforço mecânico do corpo para se deslocar no espaço de forma organizada, enquanto o gesto traz a carga expressiva, a identidade sócio psíquica de cada um/a, a sua mitologia corporal. Segundo a autora é importante criar um espaço invisível para que se possa ler a movimentação das crianças, pois assim, poderemos ver as pistas de sua história pessoal e cultural, identificadas por meio de seus movimentos e pré-movimentos. Além disso, ressalta a importância de entendermos que as crianças podem compreender e sentir seus corpos e suas movimentações de formas criativas e, ao mesmo tempo, criarem e comporem suas danças. Cabe às/aos professoras/es apresentarem a 
dança às crianças de forma que não se limite à cópia de movimentos, mas sim, um trabalho de reflexão sobre o que se faz em processo.

\section{Por uma Educação Infantil que dança: algumas considerações}

A dança é uma linguagem que comunica algo através do seu corpo, que você expressa, que você se conhece, que você pesquisa quem você é, qual é a sua estrutura internamente, como você se comunica consigo mesmo a partir desse conhecimento do seu próprio corpo com outro e com os outros. Você expressa o quê? As vezes é uma ideia, as vezes uma grande emoção, as vezes é meu sentimento, estou com vergonha, estou muito feliz, sou mais solto, me mostro mais e às vezes ultrapasso o meu limite e o limite do outro. E ela é uma educação, uma educação do corpo [...] a dança é alegria, prazer, eu brinco, é brincadeira dançar, isso traz uma felicidade (Entrevista com professora, 04/11/2016).

Podemos compreender, pela fala da professora pesquisada, a importância da dança na Educação Infantil, no que diz respeito a sua comunicação com os outros, por meio dos gestos e movimentos, do autoconhecimento e da alegria que a dança proporciona a todas as pessoas. As propostas em dança observadas possibilitavam experiências corporais de forma investigativa e criativa, além de provocarem à consciência as estruturas dos corpos e de suas gestualidades, incentivando a criação, a pesquisa individual e coletiva dos movimentos, e a improvisação através dos jogos e dinâmicas que eram construídos junto às crianças.

Os estudos teóricos realizados durante a pesquisa, até o momento, e as observações das crianças e das propostas em dança têm revelado que não podemos mais pensar em uma Educação Infantil com os corpos cerceados e impedidos de movimento. Um ambiente composto por contextos sensíveis e criativos, um espaço e tempo favoráveis à criação e troca entre as crianças e professora contribuíam para que as crianças pudessem expressar seus modos de ser e de estar no mundo como sujeitos ativos, participativos e transformadores. Foram identificados, assim, outras referências de tempo e de espaço, de percepção dos corpos, de possibilidades de movimentos, de descobertas, de conscientização corporal e de relações com o pertencimento e com a diversidade cultural.

Apesar das propostas em dança, na Creche/Pré-Escola pesquisada, ser de apenas uma hora, uma vez por semana, as corporeidades vivenciadas em dança ampliavam-se para outros espaços da Creche e em diversos momentos da jornada educativa, como nas festas, nas formas como as pessoas se comunicavam e, principalmente, como as crianças apropriavam-se dos espaços e tempos em que permaneciam na instituição, pulando, cantando, dançando, saltando, girando, encenando, interpretando...

Não há como deixar de fazer críticas às danças propostas como técnicas codificadas praticadas na Educação Infantil, que impedem o diálogo com a criação, as sensações e descobertas dos corpos das crianças, além de não respeitarem e valorizarem as diferenças de gênero, de idade, de classe social, etc. As danças com passos pré-determinados e coreografias prontas têm seu próprio lugar, mas são menos apropriadas para as crianças pequenas, ou se concebidas unicamente como ensino de dança na escola. 
Conhecer outras realidades por meio de seus próprios corpos, como tem sido observado nas propostas com as crianças, tem se revelado muito mais do que apenas “[...] desenvolver um trabalho de consciência corporal”, mas também, de "[...] desenvolver a consciência do ser, experimentando e conhecendo o mundo; não só privilegiar as habilidades corporais, mas também o sentir, o refletir, o verbalizar, o expressar-se" (Cavalari, 2005, p. 45 apud Ferreira, 2009, p. 35), pois as artes são provocadas pelos sentidos, experimentadas, construídas e apropriadas em processos criativos.

A ideia de que o espaço e tudo o que contém nele pode ser o disparador para a transformação dos corpos, pôde ser presenciado diversas vezes durante a realização da pesquisa. Como, por exemplo, a proposta com as crianças a partir das obras de Pablo Picasso, durante aproximadamente um mês. As Imagens 1, 2 e 3 revelam que as crianças foram se apropriando dos gestos e movimentos observados nas obras, reproduzindo alguns, criando outros novos, evidenciando que seus corpos não podem ser compreendidos como produtos prontos. Eles vão se transformando, se constituindo, se expressando na medida em que precisam criar soluções no espaço e no tempo. Esses fluxos contínuos de transformações nos levam, e também as crianças, a descobrir outras possibilidades de expressividades performáticas e sensíveis (Mariana, 2010), de organização dos corpos, assim como, dos tempos e espaços educativos.

Para isso, uma Educação Infantil dançante exige tempos e espaços diferenciados dos que são impostos. Para respeitar as expressões e manifestações presentes nos corpos das crianças não basta conceber os processos pedagógicos a partir de um espaço físico e de um tempo cronológico delimitado, mas sim, que tenham centralidade nos corpos das crianças e das/os professoras/es, e nas formas como ocupam e se apropriam destes, como uma unidade, ou seja, não separando suas criações dos tempos e espaços de seus corpos. 


\section{Referências}

Almeida, Fernanda. (2016). Que dança é essa?: uma proposta para a Educação Infantil. São Paulo: Summus.

Anselmo, Viviane. (2018). Educação Infantil, Dimensão Brincalhona e Profissão Docente: o que professoras e professores têm aprendido com as meninas e meninos pequenos? Dissertação de Mestrado, FEUSP, São Paulo.

Aquino, Ligia. (2015). Educação da infância e pedagogias descolonizadoras: reflexões a partir do debate sobre identidades. In: Faria, Ana Lúcia. et al. (orgs.). Infâncias e pós-colonialismo: pesquisas em busca de pedagogias descolonizadoras. Campinas/SP: Leitura Crítica; Associação de Leitura do Brasil, ALB.

Arelaro, Lisete Regina (2005). Não só de palavras se escreve a Educação Infantil, mas de lutas populares e do avanço científico. In: Faria, Ana Lúcia e Mello, Suely. (orgs.). O mundo da escrita no universo da pequena infância. Campinas/SP: Autores Associados, p.23-50.

Auroux, Sylvain. (1992). A revolução tecnológica da gramatização. Campinas/SP: Editora da UNICAMP.

Banana, Adriana. (2015). Espaço como fluxos de possibilidades. In: Salzstein, Sônia. et al. Bastos, Helena. (org.).

Corpo e Cidade: moveres entre aproximações e distanciamentos. São Paulo: Cooperativa Paulista de Dança, p. 61-70.

Barbosa, Maria Carmem. (2013). Tempo e Cotidiano - tempos para viver a infância. Leitura: Teoria e Prática.

Campinas/SP, v.31, n.61, nov., p.213-222.

Bauman, Zygmunt. (2003). Modernidade Líquida. Rio de Janeiro: Zahar.

Bufalo, Joseane. (1997). Creche: lugar de criança, lugar de infância. Dissertação de mestrado, FE-UNICAMP, Campinas/SP.

Brasil. (1995/2009). Critérios para um atendimento em creches que respeite os direitos fundamentais das crianças. MEC, SEF, Brasília/DF.

Carlos, Ana. (1996). O lugar no/do mundo. São Paulo: Hucitec.

Comissão de Mobilização de Pais e Funcionários das Creches da USP. (2015). Dossiê em defesa das creches/pré-escolas da Universidade de São Paulo. São Paulo, abril. Recuperado de: https://crechecentraluspcom.wordpress. com/2015/04/dossie12.pdf.

Daolio, Jocimar. (1995). Da cultura do corpo. Campinas/SP: Papirus.

Edwards, Carolyn; Forman, George e Gandini, Lella. (1999). As cem linguagens da criança: abordagem de Reggio Emilia na educação da primeira infância. Porto Alegre/RS: Artes Médicas Sul Ltda.

Faria, Ana Lúcia. (1999). A contribuição dos parques infantis de Mario de Andrade para a construção de uma pedagogia da educação infantil. Educação \& Sociedade. Campinas/SP: CEDES, ano XX, n.69, dez., p.60-91. Recuperado de: http://www.scielo.br/pdf/es/v20n69/a04v2069.pdf.

Faria, Ana Lúcia e Richter, Sandra. (2009). Apontamentos Pedagógicos sobre o papel da arte na educação da pequena infância: como a pedagogia da Educação Infantil encontra-se com a arte? Small Size Paper. Experiencing Art in Early Years: learning and development processes and artistic language, Bologna/IT: Pendragon, p. 103-113. 
Fernandes, Florestan. (2004). As “Trocinhas” do Bom Retiro: contribuição ao Estudo Folclórico e Sociológico da Cultura e dos Grupos Infantis. Pro-Posiçôes. FE-UNICAMP, Campinas/SP, v.15, n.1 (43), jan./abr., p.229-250.

Ferreira, Saralivia. (2009). Dança na escola: um processo de criação. Dissertação de Mestrado, FE-UNICAMP, Campinas/SP.

Foucault, Michel. (1971). A ordem do discurso. Paris/FR: Gallimard.

Franco, Berenice. (2001). A importância da corporeidade na formação do profissional da Educação Infantil. In: Roman, Eurilda e Steyer, Vivian. (orgs.). A criança de 0 a 6 anos e a educação infantil: um retrato multifacetado. Canoas/RS: Editora da ULBRA, p.259-265.

Freire, Paulo. (1983). Pedagogia do Oprimido. 12a ed., Rio de Janeiro: Paz e Terra.

Freire, Paulo (2000). Pedagogia da indignação: cartas pedagógicas e outros escritos. 6a ed., São Paulo: UNESP.

Freire, Paulo (2008). Medo e ousadia. São Paulo: Paz e Terra.

Freire, Paulo e Macedo, Donaldo. (1990). Alfabetização: leitura do mundo leitura da palavra. Rio de Janeiro: Paz e Terra.

Gobbi, Márcia. (2011). Desenhos de outrora, desenhos de agora: Mário de Andrade colecionador de desenhos e desenhista. São Paulo: Annablume, FAPESP.

Goettems, Milene Braga. (2012a). Iniciação Científica, FEUSP, São Paulo.

Goettems, Milene Braga. (2019). O tempo da infância que dança: um estudo sobre as relaçóes entre dança e subversão do tempo linear da educação infantil. Tesis de Maestría em Educación, FEUSP, São Paulo.

Laban, Rudolf. (1978). O Dominio do movimento. São Paulo: Summus.

Larrosa, Jorge. (2004). O enigma da infância: ou o que vai do possível ao verdadeiro. In: Pedagogia profana: danças, piruetas e máscaras. $4^{\mathrm{a}}$ ed., Belo Horizonte/MG: Autêntica.

Lopes, Elisabeth. (2015). Geometrias inertes, geometrias dançantes. n: Salzstein, Sônia. et al. Bastos, Helena. (org.). Corpo e Cidade: moveres entre aproximações e distanciamentos. São Paulo: Cooperativa Paulista de Dança, p.21-27.

Machado, Marina. (2010). A Criança é Performer. Educação e Realidade. FACED-UFRGS, Porto Alegre/RS, v.35, n 02, maio/ago., p.115-137.

Marcellino, Nelson. (1990). Pedagogia da animação. Campinas/SP: Papirus.

Miller, Jussara. (2012). Qual é o corpo que dança?: dança e educação somática para adultos e crianças. São Paulo: Summus.

Miller, Jussara e Neves, Neide. (2013). Técnica Klauss Vianna - Consciência em Movimento. Revista do Lume. UNICAMP, Campinas/SP, n.3, set., p.01-07. Recuperado de: http://www.cocen.unicamp.br/revistadigital/index.php/lume/article/viewFile/258/242.

Perrotti, Edmir. (1982). A Criança e a Produção Cultural: Apontamentos sobre o lugar da criança na cultura. In: Zilbermann, Regina. (org.). A produção cultural para a criança. Porto Alegre/RS, Mercado Aberto, p.09-27. 
Prado, Patricia Dias. (2012b). Educação e Culturas Infantis: crianças pequenininhas brincando na creche.

São Paulo: Képos/Laços.

Prado, Patricia Dias. (2015a). Educação Infantil: contrariando as idades. São Paulo: Képos/Laços.

Prado, Patricia Dias. (2015b). Por um Pedagogia da Educação Infantil de corpos inteiros. In: Melo, José Carlos e Chahini, Thelma. (orgs.). Reflexões \& Práticas na Formação Continuada de Professores na Educação Infantil.

São Luís/MA: EDUFMA. 205-219.

Prado, Patricia Dias. (2017b). ¿Cómo hacen eso? Entrevistando artistas, refletindo sobre Dança e Teatro na Educação da primeira infância. In: Almeida, Rogério e Beccari, Marcos. (orgs.). FLUXOS CULTURAIS: ARTE, EDUCAÇÃO, COMUNICAÇÃO E MÍDIAS. Livros Abertos FEUSP, São Paulo. 371-392.

Faria, A. L. G, De Martini, Zeila B., Prado, Patricia Dias (orgs). (2009). Por uma cultura da infância: metodologias de pesquisa com crianças. 3ª ed., Campinas/SP: Autores Associados.

Prado, Patricia Dias y Souza, Cibele W. de. (2017). Educação Infantil, Diversidade e Arte.

São Paulo: Képos/Laços.

Quijano, Aníbal. (2005). Dom Quixote e os moinhos de vento na América Latina. Estudos Avançados.

São Paulo, v.19, n.55, set./dez. Recuperado de: http://www.scielo.br/scielo.php?script=sci_arttext\&pi$\mathrm{d}=$ S0103-40142005000300002.

Rengel, Lenira. (2006). Fundamentos para análise do movimento expressivo. In: Mommensohn, Maria e Petrella, Paulo (orgs). Reflexóes sobre Laban, o mestre do movimento. São Paulo: Summus, p.121-130.

Sabino, Jorge e Lody, Raul. (2011). Danças de Matriz Africana: antropologia do movimento. Rio de Janeiro: Pallas.

Salzstein, Sônia. (2015). Os múltiplos espaços dentro do corpo. In: Salzstein, Sônia. et al. Bastos, Helena. (org.). Corpo e Cidade: moveres entre aproximações e distanciamentos. São Paulo: Cooperativa Paulista de Dança, p. 21-27.

Sayão, Deborah. (2008). Cabeças e corpos, adultos e crianças: cadê o movimento e quem separou tudo isso? Revista Eletrônica de Educação. São Carlos/SP: UFSCar, v.02, n.02, nov., p.92-105.

Silva, Adriele. (2017). Teatro para bebês: Desafios em cena para as Artes e a Educação na primeiríssima infância. Dissertação de Mestrado, FEUSP, São Paulo.

Souza, Cibele. (2016). Educação infantil e Teatro: um estudo sobre as linguagens cênicas em propostas formativas, educativas e infantis da RMS/SP. Dissertação de Mestrado, FEUSP, São Paulo.

Tadra, Debora; Viol, Rosemara e Ortolan, Sabrina. (2009). Metodologia do ensino de artes: Linguagem da Dança. Curitiba/PR: Ibpex.

Thompson, Edward. (1991). O tempo, a disciplina do trabalho e o capitalismo industrial. In: Silva, Tomás. (org.). Trabalho, educação e prática social. Porto Alegre/RS: Artes Médicas, p.44-93.

Xavier, Uxa. (2007). Que dança é essa? In: Lengos, Geórgia. (org.). Póe o dedo aqui: reflexões sobre dança contemporânea para crianças. São Paulo: Terceira Margem, p.54-65. . (2014). Mapas para dançar em muitos lugares. São Paulo: Patuá. 